\title{
Middle Third of the Esophagus
}

National Cancer Institute

\section{Source}

National Cancer Institute. Middle Third of the Esophagus. NCI Thesaurus. Code C12254.

The middle one third of the esophagus in which the muscle layer is composed of muscle cells of the striated and smooth types. 